\title{
Dysautonomic Arrhythmogenesis: A Working Hypothesis in Chronic Chagas Cardiomyopathy
}

Roberto Coury Pedrosa

Universidade Federal do Rio de Janeiro, Rio de Janeiro, RJ - Brazil.

\begin{abstract}
Sudden cardiac arrest (SCA) represents the most dramatic course of chronic Chagas cardiomyopathy (CCC) and is closely related to the presence of ventricular arrhythmias and heart disease. Although several aspects of ventricular arrhythmias in CCC have been elucidated in the last decades, such as the role of impaired cardiac autonomic modulation reported in pre-clinical studies, important questions remain unresolved regarding these cardiac problems and SCA. The aim of this article is to discuss recent developments in the understanding of the role played by the autonomic nervous system on arrhythmic events in CCC. We draw attention to the neurogenic theory of CCC ("catecholamine-induced cardiomyopathy") and its autoimmune regulation. Finally, we contextualize treatment strategies for Chagas disease considering the prevention of malignant ventricular arrhythmias. The most clinically relevant message from this article may be the high negative predictive value of dysautonomia for SCA in CCC. Nevertheless, there is a long journey from the identification of a potential marker for SCA to its actual use, which will require a common effort by the entire Chagas community.
\end{abstract}

\section{Introduction}

Chagas disease (Chd), caused by Trypanosoma cruzi, is a life-threatening and persistent illness. ${ }^{1}$ The World Health Organization (WHO) estimates that over one million

\section{Keywords}

Chagas Cardiomyopathy; Chagas Disease; Primary Dysautonomia; Arrhythmias, Cardiac; Sudden Cardiac Arrest. people suffer from chronic Chagas cardiomyopathy (CCC) in non-endemic countries, ${ }^{2}$ where its prevalence is currently rising. The number of deaths from CCC complications is expected to double with the increase in immigration observed in the last few decades in Europe and the United States. ${ }^{3}$

In Brazil, human Chd is still a major public health problem. ${ }^{4}$ In 2010 (data reviewed in 2015), the WHO estimated 1156821 infected people and 231364 people with CCC, ${ }^{5}$ leading to 6000 fatal cases per year; these numbers represent around $48 \%$ of all deaths caused by human Chd in Latin America. ${ }^{4}$ Given the chronic nature of human Chd and the increased life expectancy in Brazil, it can be assumed that mortality due to this disease will remain high in the next decades. In addition, the treatment of the infection has shown no benefits once CCC is established, ${ }^{6}$

Chd has a variable clinical presentation (further discussed in. 7) The T. cruzi infection is followed by a short acute phase, which is usually self-limited and is asymptomatic in $95 \%$ of the patients; most acute infections are never clinically detected. In less than $1 \%$ of infections, the acute phase is severe and life-threatening due to meningoencephalitis or myocarditis. ${ }^{7}$ Rather surprisingly, there is still no known proven cure. ${ }^{8}$ Acute cases of greater severity resulting from a higher parasitic burden tend to evolve into forms of CCC that are also more severe. ${ }^{9}$ The CCC is identified from an electrocardiographic alteration compatible with Chd, as discussed in. ${ }^{6}$ In most cases, the disease enters its longlasting chronic phase starting with the indeterminate form: a long and latent stage of the infection. While most patients infected with T. cruzi will remain in the indeterminate form for a lifetime, illustrating that organ/ tissue aggression remains controlled in many patients, according to early studies (contemporary natural history

Mailing Address: Roberto Coury Pedrosa

Rua Prof. Rodolpho Paulo Rocco, 255. Postal Code: 21941-913, Cidade Universitária, Rio de Janeiro, RJ - Brazil.

E-mail: coury@hucff.ufrj.br 
information is scarce, ${ }^{10)}$ around $20-30 \%$ will develop clinically manifest lesions 10 to 30 years after the infection, mainly in the heart ${ }^{3}$ and usually with a mild presentation

${ }^{9}$ During this long disease progression period, recent literature revealed that the annual incidence of the cardiac form is relatively low, at $1.85 \% .^{10}$

CCC is highly arrhythmogenic, more than other cardiomyopathies. ${ }^{6}$ It is characterized by severe ventricular arrhythmia beyond the typical conduction system defects, especially with a right bundle branch block and/or left anterior fascicular block ${ }^{11-13}$ in the various stages of Chagas disease (often called the "silent killer"). One of the main modes of death is sudden cardiac death ([SCD] $55 \%-65 \%$ ), of which $90 \%$ of cases are due to sustained ventricular tachycardia (SVT)/ ventricular fibrillation (VF) clinically manifest as SCD or sudden cardiac arrest (SCA)/resuscitated SCD. ${ }^{14-17}$ In this regard, according to Laranja et al.,$^{18}$ the potential risk of sudden death should be considered in Chagas patients with evidence of cardiac involvement. Indeed, SCA in Chd is closely related to heart disease ${ }^{14}$ but not all patients with complex ventricular arrhythmias will develop SCA. Although there is no absolute proof that pathogen-induced cardiac remodeling ${ }^{19}$ is synonym to arrhythmic death in patients, ie, that halting cardiac remodeling could prevent SCA, there is a consensus that cardiac autonomic dysfunction is required for SCA to occur. ${ }^{20}$ Gadioli et al., in a study that analyzed the electrophysiological substrate of complex ventricular arrhythmias in CCC, suggested that factors other than the severity of the left ventricular dysfunction and the presence of regional myocardial fibrosis are likely to contribute to the genesis of these complex ventricular arrhythmias and ultimately SCA. ${ }^{21}$

Thus, the present article aims to highlight recent developments in our understanding of the role played by the autonomic nervous system on arrhythmic events in CCC. We also discuss the neurogenic theory of chronic Chd ("catecholamine-induced cardiomyopathy") and its autoimmune regulation. Finally, we present current treatment strategies for the prevention of malignant ventricular arrhythmias.

The Role of Autonomic Imbalance on Sudden Cardiac Arrhythmic Death

The detection of cardiac dysautonomia is a source of information when resolving the clinical enigma of sudden and unexpected death, particularly in CCC ${ }^{20}$. The type and sequence of dysautonomic events that explain cardiac arrest (detailed in Table 1) are a matter of discussion. CCC is a unique condition because of the association between autonomic nervous system impairment and an increasing number of complex ventricular arrhythmias. ${ }^{20-24}$

\section{Evidence from Histopathology Studies}

It seems likely that most or all patients with Chagas disease undergo major pathological changes in the intertruncal plexus; these changes are among the least recognized but exceptionally important aspects of CCC. Alterations such as ganglionitis, periganglionitis, neuritis, and perineuritis are present during Chagas infection, with neural depopulation and a marked reduction in ganglionic density in both humans and experimental animal models. ${ }^{25}$ These changes predominantly occur during the acute phase of the Chagas infection by a combination of 3 factors: direct parasitism of neurons, degeneration caused by periganglionic inflammation, and an antineuronal autoimmune reaction. ${ }^{26}$

The pathological changes in the intertruncal plexus in human Chd are so remarkable that some researchers consider them the main mechanism leading to SCD. Reviews of studies on cardiac autonomic dysfunction explain the presence of ventricular arrhythmias in the non-remodeled ventricle as a result of a prolonged autonomic imbalance. This imbalance is in turn caused by an intense and early parasympathetic neuronal depopulation, which would eventually lead to a "catecholamine-induced cardiomyopathy". ${ }^{27}$

Studies using animal models showed that neuronal cell death occurs mainly or exclusively during the acute phase ${ }^{28,29}$ Nevertheless, the autonomic neurons have a high capability for axonal regrowth or sprouting. ${ }^{30}$ and sympathetic reinnervation was reported in humans during the chronic phase of Chd after procedures such as heart transplantation and stem cell therapy. ${ }^{31,32}$ However, the re-establishment of functional neuroeffector junctions due to axonal regeneration during the chronic phase is disorganized, random, and not complete. The parasympathetic innervation presents an analogous behavior: a marked destruction of nervous fibers and a decrease in heart acetylcholine (ACh) levels during the acute phase, followed by functional re-establishment in a disorganized, random, and incomplete manner during the chronic phase. ${ }^{28}$ It is still unclear why parasympathetic denervation appears more intense than sympathetic denervation, leading to 
the "catecholamine-induced cardiomyopathy" present in the realm of the neurogenic theory for Chd; it is possible that the localization of post-ganglionic neurons of the parasympathetic system in the heart may lead to greater damage and a slower reinnervation rate, since neuronal damage seems to be restricted to the nerve terminals ${ }^{28}$. In fact, this residual cardiac sympathetic activation was demonstrated in studies with iodine- 123 metaiodobenzylguanidine (123I-MIBG) scintigraphy, where myocardial sympathetic innervation was indicated by an increased 123I-MIBG washout rate. This could be the result of relatively increased cardiac sympathetic activity at the early stage of CCC, supporting the neurogenic theory stated above. ${ }^{23,33,34}$ More importantly, the vagalcholinergic pathway plays a direct role in preventing the initiation of complex ventricular arrhythmias, including non-sustained ventricular tachycardia (NSVT) and ventricular fibrillation. ${ }^{35,36}$

Corroborating previous reports, a recent study used myocardial scintigraphy with 123I-MIBG to measure sympathetic innervation and rest myocardial perfusion using 99mTc-Sestamibi (MIBI) in Chagas patients with normal or mildly reduced left ventricular systolic function. The results indicated that the occurrence of ventricular arrhythmias of different degrees of severity correlated quantitatively with the extent of ventricular sympathetic denervation, but not of fibrosis, suggesting that myocardial sympathetic denervation played a major role in triggering these arrhythmias. ${ }^{21}$ Moreover, the presence of different degrees of myocardial sympathetic denervation in patients with similar resting myocardial perfusion imaging summed scores but different MIBG summed scores suggested that the mechanism of sympathetic neuronal damage may not be related to the microcirculation abnormalities responsible for perfusion defects. The reason why some patients with similar levels of fibrosis and perfusion defects have different amounts of denervated myocardium is still unknown, and the future understanding of the causes of neuronal damage in CCC should contribute to the design of effective treatments.

The coexistence of denervated and innervated areas ${ }^{37}$, the presence of regional myocardial fibrosis, ${ }^{37,38}$ and the potential influence of these structures in inotropic, chronotropic, and dromotropic activities in the diseased myocardium is clear. Their effects on the recovery of excitability result in an increase of the dispersion of action potential duration to a critical level ${ }^{39}$ during residual sympathetic activation and increase the propensity to ventricular arrhythmias. ${ }^{33-35,40}$ Although it is difficult to determine the independent effects of impaired cardiac autonomic modulation, it certainly influences the recovery of excitability, as recently suggested by myocardial scintigraphy studies. ${ }^{21}$ This is certainly an area of research that merits further investigation. Differences in the response to residual sympathetic activation can be due to heterogeneous sympathetic innervation or ion channel distribution, in addition to myocardial remodeling and the resultant ventricular electrophysiological effects. ${ }^{41}$

\section{The Mechanism of Autonomic Dysfunction}

Although the mechanism of autonomic dysfunction in CCC has yet to be clarified, studies reported the presence of circulating antibodies with the capacity of binding to cholinergic (Ac-M) as well as adrenergic (Ac- $\beta$ ) receptors. ${ }^{42-46}$ These findings could conciliate neurogenic alterations ${ }^{20}$ and an immunological aggression ${ }^{47}$ as interacting and relevant pathophysiological factors (particularly, the electrophysiological role of antibodies)

A research group at the Federal University of Rio de Janeiro, Brazil, first reported in 1994 that a humoral component could be involved in the genesis of ventricular arrhythmia in CCC. Their results indicated that sera from rabbits infected with $T$. cruzi generated atrioventricular conduction disturbances in isolated rabbit hearts. ${ }^{48}$ Three years later, we confirmed this hypothesis by showing that antibodies originated from chronic chagasic patients presenting complex ventricular arrhythmias decreased heart rates and caused atrioventricular blocking in isolated rabbit hearts. ${ }^{49}$ In line with these studies, a research group characterized 58 serum samples of patients with CCC and described that some of them had a $\beta$-adrenergic effect and induced ventricular arrhythmias through communicating junctions in a culture of newborn rat cardiomyocytes. This result suggested another mechanism through which these antibodies could contribute to the occurrence of arrhythmias. ${ }^{50}$

Until 2007, studies associated the role of antibodies to conduction disorders, focusing mainly on the atrioventricular conduction disturbance. However, they did not consider that these proteins could mediate the ventricular repolarization involvement and thus be related to the induction of ventricular arrhythmias, which are among the main causes of death in patients with CCC. ${ }^{51}$ Indeed, our group was able to show, for the first time, that patients with CCC who had antibodies with muscarinic activity presented higher QT interval 

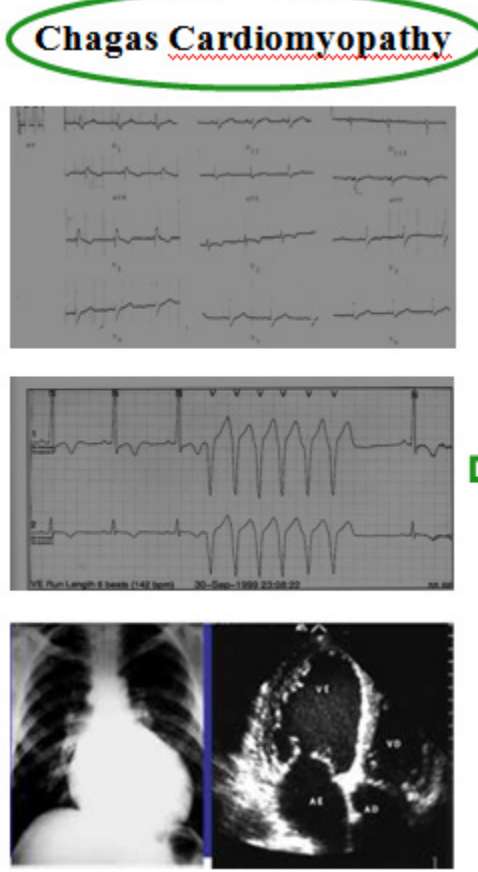

\section{Dysautonomia}

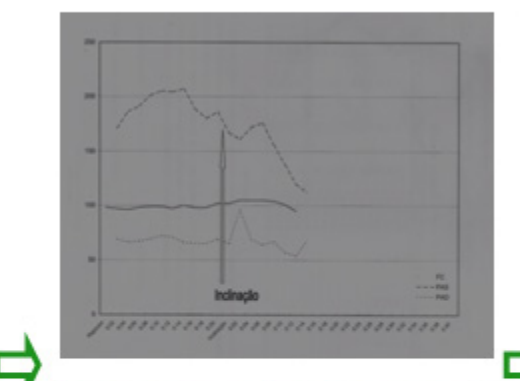

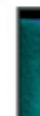

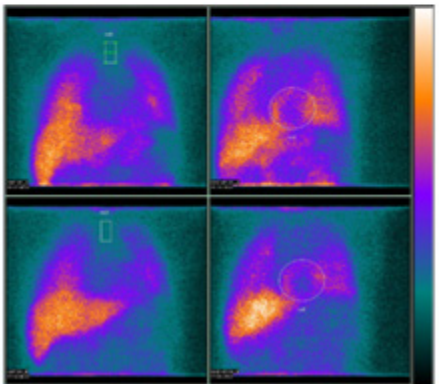

\section{Sudden Cardiac Arrest}
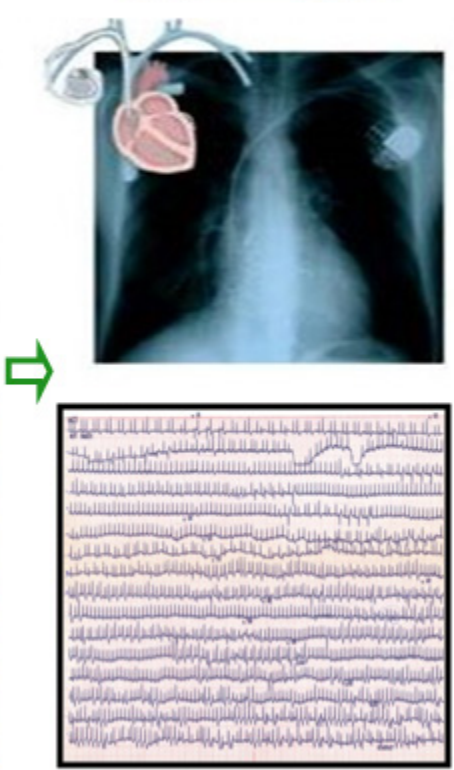

Chagas patient, male, 30 years old; ECG showed right bundle branch block + left anterior hemiblock + unsustainable monomorphic ventricular tachycardia ; echo / chest radiography revealed dilated cardiomyopathy; TILT test showed dysautonomy; myocardial scintigraphy with MIBG showed sympathetic ventricular denervation (dysautonomia); 24h-Holter highlighted several episodes of unsustainable monomorphic ventricular tachycardia. High-risk patient for sudden death, implanted ICD ECG: electrocardiography; ICD: implantable cardioverter-defibrillator.

dispersion when compared to chronic chagasic patients that did not have this type of antibody in their sera. It is worth mentioning that antibodies with a muscarinic effect, when perfused in isolated rabbit hearts under controlled heart rates, increased QT intervals. ${ }^{52}$ More recently, our group showed that autoantibodies with beta-adrenergic activity from CCC patients induced ventricular arrhythmias and early afterdepolarization in drug-induced LQT2 rabbit hearts. ${ }^{53}$

\section{The Electrophysiological Proposal}

In CCC, the prolongation of the QT interval is associated with functional re-entry, ventricular arrhythmia (especially torsade de pointes), and sudden death. Studies showed that increases in catecholamine residual levels prolong the QT interval in Chagas disease, ${ }^{52,53}$ and robust data link the presence of cardiac repolarization abnormalities and the risk of arrhythmic death in CCC. Cohort studies reported, after Cox regression adjustment for cardiovascular disease, that an abnormal QT interval or increased QT dispersion, ${ }^{54}$ as well as $\mathrm{T}$-wave axis deviation ${ }^{55}$ or primary $\mathrm{T}$-wave abnormalities in a 12-lead ECG ${ }^{56}$ were associated with an increased risk of death. Other methods of evaluating repolarization variability, such as $\mathrm{T}$-wave amplitude variability ${ }^{56}$ and $\mathrm{T}$-wave spatial heterogeneity, ${ }^{57}$ were independently associated with higher risk in a relatively small cohort. Finally, microvolt T-wave alternans, evaluated by a commercial method and useful in other conditions, is abnormal in CCC, ${ }^{58}$

Nevertheless, a consensus emerges from these studies that successful risk assessment of patients with CCC needs to involve a combination of different indices that reflect not only the pathological substrate but also the autonomic regulation of cardiac electrophysiology. It is important to state that pre-existing electrophysiological heterogeneity is a sine qua non for ventricular arrhythmias to occur. In fact, some studies aimed at addressing this requirement used the dynamic beat-to-beat method as a measure of repolarization heterogeneity. ${ }^{41,59}$ It is nonlinear, highly dynamic, occurs independently from underlying heart rate variability, and varies with normal and abnormal physiological conditions, including autonomic state. It is also important to note that there 
is no correlation between QT dispersion, a conceptually flawed measure of repolarization heterogeneity, and the dynamic beat-to-beat method. ${ }^{60}$

Recent studies analyzed the electrical restitution heterogeneity in another disease ${ }^{61,62}$ and suggested autonomic modulation as a factor that contributed to the break-up of the electrical wave front, increasing the propensity to ventricular arrhythmias.

Some researchers suggest dynamic beat-to-beat analysis as a promising novel biomarker of SCD risk in ischemic cardiomyopathy. ${ }^{36,41,59,61-66}$ Ongoing clinical studies, including a multicenter British study, are being conducted to consolidate the evidence base for periodic repolarization dynamics and develop a successful clinical tool for the assessment of SCD risk. ${ }^{62}$ In Brazil, our group has explored the potential role of dynamic beat-to-beat analysis in SCA risk stratification in CCC. MobileECG, a ubiquitous platform that explores beat-to-beat dynamics over collaborative databases, is currently being developed for its application in the Brazilian Unified Health System in patients with CCC. ${ }^{67}$

\section{Therapeutic Perspectives}

After more than three decades dedicated to vector control and blood safety programs with successful results, the approach to Chagas disease by the scientific community and global health policy makers is entering a new phase. Today, the main priorities of international funders are treatment models that may produce clinical effects in the patients. The future will rely on the search for new therapeutic strategies that are efficient and well tolerated, reflecting in the clinical improvement of patients with this neglected tropical disease.

As previously mentioned, ventricular arrhythmias are very common in patients with CCC, ${ }^{6}$ and sustained rapid ventricular tachycardia is recognized as the most important cause of sudden cardiac death in Chagas heart disease. ${ }^{68}$ It has been identified in patients with segmental diseases, with or without important ventricular dysfunction, and ICD implants are recommended to prevent sudden cardiac death. ${ }^{68,69}$ However, the use of ICDs is hampered by the lack of controlled data to establish precise indications and efficacy. ${ }^{70-72} \mathrm{In}$ fact, the evidence on the use of amiodarone, $\beta$-blockers, enzyme inhibitors, aldosterone blockers, ${ }^{73}$ and devices such as the ICD is not yet conclusive to support or reject their use, ${ }^{71,72}$ which is recommended based on limited observational data and the extrapolation of results from other patient populations.
Official statistics record about 12,500 deaths due to Chd each year, with $60 \%$ (or 7,500 deaths) occurring suddenly. The annual rate of sudden death can be estimated at 0.17 to $0.19 \%,{ }^{14}$ since there are $6-7$ million infected individuals in Latin America. Thus, in order to prevent two cases of sudden death in the general chagasic patient population, any intervention should be applied to another 998 chagasic individuals who will not present any events. Particularly, the implantation of ICDs represents a high-cost intervention and requires multiple implants to save a life, since studies show that only one in every eighteen ICD implants is actually effective. This is another aspect that demonstrates the uniqueness of Chagas disease and evidences the need for identifying subgroups of sudden death risk patients that would be potential candidates for a more intensive prevention strategy.

Over the years, clinical studies showed that the vagalcholinergic pathway could play a direct role in preventing the initiation of complex ventricular arrhythmias. Unfortunately, the effects of chronic vagal stimulation (VNS) on the occurrence of arrhythmia were investigated in humans and produced unfavorable results. ${ }^{74-76}$ Similar outcomes were obtained with studies on sympathetic denervation through the use of pharmacological agents. ${ }^{77}$

At the moment, all efforts are focused on strategies to eliminate circulating antibodies with the capacity of binding to cholinergic (Ac-M) as well as adrenergic (Ac$\beta)$ receptors in patients with CCC.

A relevant and often ignored facet of CCC is the presence in nearly all cardiac chagasic patients of agonistic autoantibodies against G-protein coupled receptors, such as those against muscarinic and betaadrenergic receptors. Studies by our and other groups have extensively characterized these antibodies and showed that they can modulate electrogenesis and impulse conduction in isolated hearts. ${ }^{46-53}$ Both classes of antibodies are regarded as "drivers" of cardiac arrhythmia in CCC. Consequently, to counteract the arrhythmogenic potency of agonistic antibodies against G-protein coupled receptors, treatment strategies that focus on the removal of these antibodies by whole immunoglobulin $G$ apheresis or in vivo antibody neutralization ${ }^{78-80}$ have been developed; these could possibly have a beneficial effect in Chagas patients with complex ventricular arrhythmias that are refractory to conventional treatments. It is also necessary to explore specific and appropriate suppression times or dosedependent effects that could contribute to the control of 
complex ventricular arrhythmia and consequent SCA in CCC. In fact, this has not yet been tested in prospectively controlled, randomized human studies.

Another therapeutic option could be the use of stem cells for tissue repair. This new strategy is being intensely investigated in clinical assays ${ }^{81}$.

\section{Concluding Remarks}

Although several aspects of ventricular arrhythmias in CCC have been elucidated in the last decades, important questions regarding the mechanisms of sudden arrhythmic death remain unresolved. While pre-clinical studies have documented the role of impaired cardiac autonomic modulation in ventricular arrhythmias, the translational aspects of this modulation have not yet been fully defined. Thus, understanding the function of autonomic modulation in the clinical severity of ventricular arrhythmias in CCC is an important focus point for future studies. It is also reasonable to believe that a set of autonomic modulation markers, rather than a single "magic bullet", might be needed to ensure adequate correlation with sudden arrhythmic death. The use of retrospective cohorts could be envisaged, but a large prospective study (clinical trial with long follow-up of patients) might be required to verify if autonomic modulation markers are surrogates for sudden

\section{References}

1. Chagas C. Uber eine neue Trypanosomiasis des Menschen. Archiv für Schiffs - und Tropen - Hygiene. 1909; 13:351-3;

2. Rechel B, Mladovsky P, Ingleby D, Mackenbach JP, McKee M. Migration and health in an increasingly diverse Europe. Lancet. 2013; 381: 1235-45.

3. Gascon J, Bern C, Pinazo MJ. Chagas disease in Spain, the United States and other non-endemic countries. Acta Trop. 2010;115(1-2):22-7.

4. Martins-Melo FR, Ramos Jr NA, Alencar CH, Heukelbach J. Mortality due to Chagas disease in Brazil from 1979 to 2009: trends and regional differences. J Infect Dev Ctries. 2012; 6(11): 817-24.

5. World Health Organization. (WHO. Chagas Disease (American trypanosomiasis). [Cited in $202004 \mathrm{Feb}$ ] Available at: http://www.who. int/mediacentre/factsheets/fs340/en/ . 2017.

6. Dias JC, Ramos AN Jr, Gontijo ED, Luquetti A, Shikanai-Yasuda MA, Coura JR, et al. [Brazilian Consensus on Chagas Disease, 2015]. Epidemiol Serv Saude. 2016;25(especial):7-86

7. Rassi A, Rezende JM, Luquetti AO, Rassi A Jr. Clinical phases and forms of Chagas disease. In: Telleria J, Tibayrenc M (eds) American trypanosomiasis (Chagas disease). One hundred years of research .Burlington:Elsevier; 2010. P.709-41.

8. Dias JC, Dias E, Martins-Filho OA, Vitelli-Avelar D, Correia D, Lages E, et al Further evidence of spontaneous cure in human Chagas disease. Rev Soc Bras Med Trop. 2008; 41(5):505-6.

9. Borges-Pereira J, Willcox HP, Coura JR. Morbidade da doença de Chagas. III - Estudo longitudinal de seis anos em Virgem da Lapa, MG, Brasil. Mem Inst Oswaldo Cruz. 1985;80(1):63-71. arrhythmic death. In either case, this is an endeavor that requires a unified effort from the entire Chagas community, and perhaps the most clinically relevant message from this article may be the high negative predictive value of dysautonomia regarding SCA in CCC.

\section{Author Contributions}

Conception and design of the research: Pedrosa RC. Acquisition of data: Pedrosa RC. Analysis and interpretation of the data: Pedrosa RC. Writing of the manuscript: Pedrosa RC. Critical revision of the manuscript for intellectual content: Pedrosa RC.

\section{Potential Conflict of Interest}

No potential conflict of interest relevant to this article was reported.

\section{Sources of Funding}

There were no external funding sources for this study.

\section{Study Association}

This study is not associated with any thesis or dissertation work.

10. Sabino EC, Ribeiro AL, Salemi VMC, Di Lorenzo Oliveira C, Antunes AP, Menezes MM et al. Ten-year incidence of Chagas cardiomyopathy among asymptomatic Trypanosoma cruzi-seropositive blood donors. Circulation. 2013;127(10):1105-15.

11. Pedrosa RC; Cancado JR; Decache W. A longitudinal electrocardiogram study of Chagas' disease from the acute phase. Rev Soc Bras Med Trop. 1993;26(3):163-74.

12. Ribeiro AL, Marcolino MS, Prineas RJ, Lima-Costa MF. Electrocardiographic abnormalities in elderly Chagas disease patients: 10-year follow-up of the Bambui Cohort Study of Aging. J Am Heart Assoc. 2014;3(1):e000632.

13. Cardoso R, Garcia D, Fernandes G, Li He BA, Lichtenberger P, Gonzales JV et al. The Prevalence of Atrial Fibrillation and Conduction Abnormalities in Chagas' disease: A Meta-Analysis. J Cardiovasc Electrophysiol. 2016;27(2):161-9.

14. Rassi A Jr, Rassi SG, Rassi A. Sudden death in Chagas' disease. Arq Bras Cardiol. 2001;76(1):75-96.

15. Rassi A Jr, Rassi A,Rassi SG. Predictors of Mortality in Chronic Chagas Disease A Systematic Review of Observational Studies. Circulation. 2007;115(9):1101-8.

16. Baroldia G, Oliveira JMS, Silver MD. Sudden and unexpected death in clinically 'silent' Chagas' disease. A hypothesis. Int J Cardiol. 1997;58(3):263-8.

17. Braggion-Santos MF, Jardim Volpe G, Pazin-Filho A, Maciel BC, MarinNeto JA, Schmidt A. Sudden Cardiac Death in Brazil: A CommunityBased Autopsy Series (2006-2010) Arq Bras Cardiol. 2015;104(2):120-7. 
18. Laranja FS. Clinical aspects of Chagas' disease. Rev Bras Med. 1953;10(7):482-91.

19. Bonney KM, Luthringer DJ, Kim SA, Garg NJ, Engman DM. Pathology and pathogenesis of Chagas heart disease. Ann Rev Pathol: Mechan Dis 2019;14:421-47.

20. Junqueira LF. Sobre o possível papel da disfunção autonômica cardíaca na morte súbita associada à doença de Chagas. Arq Bras Cardiol. 1991;56(6):420-34.

21. Gadioli LP, Miranda CH, Pintya AO, de Figueiredo AB, Schmidt A, Maciel $\mathrm{BC}$, et al.The severity of ventricular arrhythmia correlates with the extent of myocardial sympathetic denervation, but not with myocardial fibrosis extent in chronic Chagas cardiomyopathy: Chagas disease, denervation and arrhythmia. J Nucl Cardiol. 2018;25(1):75-83.

22. Cunha AB, Cunha DM, Pedrosa RC, Flammini F, Silva AJ, Saad EA, et al. Norepinephrine and heart rate variability: a marker of dysautonomia in chronic Chagas cardiopathy. Rev Port Cardiol. 2003; 22(1):29-52.

23. Landesmann MC, da Fonseca LM, de B Pereira B, do Nascimento EM, Rosado-de-Castro PH, de Souza SA et al. Iodine-123 metaiodobenzylguanidine cardiac imaging as a method to detect early sympathetic neuronal dysfunction in chagasic patients with normal or borderline electrocardiogram and preserved ventricular function Clin Nucl Med. 2011; 36(9):757-61

24. Merejo Peña CM, Reis MS, Pereira BB, Nascimento EMD, Pedrosa RC. Dysautonomy in different death risk groups (Rassi score) in patients with Chagas heart disease. Pacing Clin Electrophysiol. 2018;41(3):238-45.

25. James, TN; Rossi, MA; Yamamoto S. Postmortem Studies of the Intertruncal Plexus and Cardiac Conduction System From Patients With Chagas Disease Who Died Suddenly. Progr Cardiovasc Dis. 2005;47(4):258-75.

26. Marin-Neto JA, Cunha-Neto E, Maciel BC \& Simoes MV. Pathogenesis of chronic Chagas heart disease. Circulation. 2007;115(9):1109-13.

27. Köberle F. Cardiopathia parasympaticopriva. München Med Wschr. 1959;101:1308-10.

28. Machado ABM, Machado CRS, Gomez MV. Trypanosoma cruzi: acetylcholine content and cholinergic innervation of the heart in rats. Exp Parasitol. 1979; 47(1): 107-15

29. Machado CR; Ribeiro AL. Experimental American trypanomiasis in rats: sympathetic denervation, parasitism and inflammatory process. Mem Inst Oswaldo Cruz. 1989;84(4):549-56.

30. Machado CRS, Machado ABM, Chiari CA. Recovery of heart norepinephrine depletion in experimental Chagas' disease. Am J Trop Med Hyg.1978; 27(1pt1): 20-4.

31. Schwaiger M, Kalff V, Rosenspire K, Haka MS, Molina E, Hutchins GD, et al. Non-invasive evaluation of sympathetic nervous system in human heart by positron emission tomography. Circulation. 1990;82(2):457-64.

32. Barbosa da Fonseca LM, Xavier SS, Rosado de Castro PH, Lima RS, Gutfilen B, Goldenberg RC, et al. Biodistribution of bone marrow mononuclear cells in chronic chagasic cardiomyopathy after intracoronary injection. Int J Cardiol. 2011;16(3):310-4.

33. Simões MV, Pintya AO, Sarabanda AV, Pazin-Filho A, Maciel BC, MarinNeto JA. Reduced [123I] MIBG uptake precedes wall motion impairment in Chagas' disease. J Nucl Cardiol. 1999;6:S63.

34. Simões MV, Pintya AO, Bromberg-Marin G, Sarabanda AVL, Antloga CM, Pazin-Filho A, et al. Relation of regional sympathetic denervation and myocardial perfusion disturbance to wall motion impairment in Chagas' cardiomyopathy. Am J Cardiol. 2000;86(9):975-81.

35. Miranda CH, Figueiredo AB, Maciel BC, Marin-Neto JA, Simoes MV. Sustained ventricular tachycardia is associated with regional myocardial sympathetic denervation assessed with 123Imetaiodobenzylguanidine in chronic Chagas cardiomyopathy. J Nucl Med. 2011;52(4):504-10.

36. Brack KE, Coote JH, Ng GA. Vagus nerve stimulation inhibits the increase in $\mathrm{Ca} 2+$ transient and left ventricular force caused by sympathetic nerve stimulation but has no direct effects alone--epicardial $\mathrm{Ca} 2+$ fluorescence studies using fura-2 AM in the isolated innervated beating rabbit heart. Exp Physiol.2010;95(1):80-92.

37. Terzi FV, Siqueira Filho AG, Nascimento EM, Pereira B de B, Pedrosa RC Regional left ventricular dysfunction and its association with complex ventricular arrhythmia, in chagasic patients with normal or borderline electrocardiogram. Rev Soc Bras Med Trop. 2010; 43(5):55761.

38. Tassi EM, Continentino MA, Nascimento EM, Pereira BB, Pedrosa RC Relationship between fibrosis and ventricular arrhythmias in Chagas heart disease without ventricular dysfunction. Arq Bras Cardiol. 2014;102(5): 456-64.

39. Han, J., Moe, G.K., 1964. Nonuniform recovery of excitability in ventricular muscle. Circ.Res. 1964;14(1):44-60.

40. Nasario-Junior O, Benchimol-Barbosa PR, Pedrosa RC, Nadal J. Assessment of Autonomic Function by Phase Rectification of RR Interval Histogram Analysis in Chagas Disease. Arq Bras Cardiol. 2015; 104(6):450-5.

41. Ng GA, Mantravadi R, Walker WH, Ortin WG, Choi BR, de Groat W, et al. Sympathetic nerve stimulation produces spatial heterogeneities of action potential restitution. Heart Rhythm 2009; 6 (5): 696-706.

42. Goin JC, Borda E, Leiros CP, Storino R, Sterin-Borda L. Identification of antibodies with muscarinic cholinergic activity in human Chagas" disease: pathological implications. J Auton Nerv Syst. 1994;47(1-2):45-52.

43. Goin JC, Leiros CP, Borda E, Sterin-Borda L. Interaction of human chagasic IgG with the second extracellular loop of the human heart muscarinic acetylcholine receptor: functional and pathological implications. FASEB J. 1997;11(1):77-83.

44. Borda ES, Sterin-Borda L. Antiadrenergic and muscarinic receptor antibodies in Chagas' cardiomyopathy. Int J Cardiol. 1996;54(2):149-56.

45. Borda ES, Cossio P, Vega MV, Arana R, Sterin-Borda L. A circulating IgG in Chagas' disease wich binds to $\beta$-adrenoreceptors of myocardium and modulates their activity. Clin Exp Immunol. 1984;57(14):679-86.

46. Retondaro FC, Costa PCS, Pedrosa RC, Kurtenbach E. Presence of antibodies against the third intracellular loop of the M2 muscarinic receptor in the sera of chronic chagasic patients. FASEB J. 1999;13(14):2015-20.

47. Medei EH, Nascimento JH, Pedrosa RC, Carvalho AC. Role of autoantibodies in the physiopathology of Chagas' disease. Arq Bras Cardiol. 2008; 91(4):257-62, 281-6

48. de Carvalho AC, Masuda MO, Tanowitz HB, Wittner M, Goldenberg RCS, Spray DC. Conduction defects and arrythmias in Chagas' Disease: Possible role of gap junctions and humoral mechanisms. J Cardiovasc Electrophysiol. 1994;5(8):686-98.

49. Farias de Oliveira S, Pedrosa RC, Nascimento JHMS, Campos de Carvalho AC, Masuda MO. Sera from chronic chagasic patients with complex cardiac arrhythmias depress electrogenesis and conduction in isolated rabbit hearts. Circulation. 1997; 96(6):2031-7.

50. Costa PCS, Fortes FSA, Machado AB, Almeida NAC, Olivares EL, Cabral PR, et al. Sera from chronic chagasic patients depress cardiac electrogenesis and conduction. Braz J Med Biol Res. 2000;33(4):1-9.

51. Medei E, Pedrosa RC, Benchimol Barbosa PR, Costa PC, Hernandez CC, Chaves EA, et al. Human antibodies with muscarinic activity modulate ventricular repolarization: basis for electrical disturbance. Int J Cardiol. 2007; 115(3):373-80.

52. Medei EH, Nascimento JH, Pedrosa RC, Barcellos L, Masuda MO, Sicouri $\mathrm{S}$, et al. Antibodies with beta-adrenergic activity from chronic chagasic patients modulate the QT interval and $\mathrm{M}$ cell action potential duration. Europace. 2008; 10(7):868-76.

53. Jiménez MAV, Nascimento JHM, Monnerat G, Maciel L, Paiva CN ,Pedrosa RC, et al. Autoantibodies with beta-adrenergic activity from chronic chagasic patients induce cardiac arrhythmias and early afterdepolarization in a drug-induced LQT2 rabbit hearts. Int J Cardiol. 2017;240:354-9.

54. Salles G, Xavier S, Sousa A, Hasslocher-Moreno A, Cardoso C. Prognostic value of QT interval parameters for mortality risk stratification in Chagas' disease: results of a longterm follow-up study. Circulation. 2003;108(3):305-12. 
55. Salles GF, Cardoso CR, Xavier SS, Sousa AS, Hasslocher-Moreno A. $\mathrm{T}$-wave axis deviation as an independent predictor of mortality in chronic Chagas' disease. Am J Cardiol. 2004;93(9):1136-40.

56. Ribeiro AL, Rocha MO, Terranova P, Cesarano M, Nunes MD, Lombardi F. T-wave amplitude variability and the risk of death in Chagas disease. J Cardiovasc Electrophysiol. 2011;22(7):799-85.

57. Sassi R, Rivolta MW, Mainardi LT, Reis RC, Rocha MO, Ribeiro AL. Spatial repolarization heterogeneity and survival in chagas disease. Methods Inf Med. 2014; 53(4):464-8.

58. Raadschilders L, Barbosa MP, Carmo AA, Nouwen JL, Rocha MO, Ribeiro AL. Microvolt T-wave alternans in Chagas disease. Int J Cardiol. $2015 ; 187: 7-8$

59. Brack, K.E, Winter, J, Ng, G.A. Mechanisms underlying the autonomic modulation of ventricular fibrillation initiation - tentative prophylactic properties of vagus nerve stimulation on malignant arrhythmias in heart failure. Heart Fail. Rev. 2013; 18 (4):389-408.

60. Malik M, Batchvarov VN. Measurement, interpretation and clinical potential of QT dispersion. J. Am. Coll. Cardiol.2000; 36(6):1749-66.

61. $\mathrm{Ng}, \mathrm{G}$.A. Neuro-cardiac interaction in malignant ventricular arrhythmia and sudden cardiac death. Autonomic Neuroscience: Basic and Clinical 2016:199:66-79.

62. Ng GA, Mistry A, Schlindwein FS, Nicolson WB. LifeMap: towards the development of a new technology in sudden cardiac death risk stratification for clinical use. Europace 2018;20(Pt 2):162-70.

63. Antzelevitch C. Transmural dispersion of repolarization and the T wave. Cardiovasc Res 2001; 50: 426-431.

64. Rizas KD, Nieminen T, Barthel P, Zürn CS, Kahonen M, Viik J et al. Sympathetic activity-associated periodic repolarization dynamics predict mortality following myocardial infarction. J Clin Invest. 2014;124(4):1770-80.

65. Hanson B, Child N, Van Duijvenboden S, Orini M, Chen Z, Coronel R, Rinaldi CA et al. Oscillatory behavior of ventricular action potential duration in heart failure patients at respiratory rate and low frequency. Front Physiol Frontiers 2014;5:414

66. Rizas KD, McNitt S, Hamm W, Massberg S, Kaab S, Zareba W et al. Prediction of sudden and non-sudden cardiac death in post-infarction patients with reduced left ventricular ejection fraction by periodic repolarization dynamics:MADIT-II substudy. European Heart J. 2017;12:1-9.

67. Madeiro JPV, Cortez PC, Salinet Jr JL, Pedrosa RC, Monteiro Filho JMS, Brayner ARA. Classical and Modern Features for Interpretation of ECG Signal. In: João Paulo do Madeiro JPV, Cortez JP, Monteiro Filho JM Roncalli A, Brayner A, eds. Developments and applications for ECG signal processing: modeling, segmentation and pattern recognition. New York: Academic Press; 2019. p1-28.

68. Muratore CA, Sa LAB, Chiale PA, Eloy R,. Tentori MC, Escudero J, et al. Implantable cardioverter defibrillators and Chagas' disease: results of the ICD registry Latin America, Europace. 2009,11(2):164-8.
69. Di Toro D, Muratore C, Aguinaga L, Batista L, Malan A, Greco O, et al. Predictors of All-Cause 1-Year Mortality in Implantable Cardioverter Defibrillator Patients with Chronic Chagas' Cardiomyopathy. Pacing Clin Electrophysiol. 2011;34(9):1063-9.

70. Muratore C, Rabinovich R, Iglesias R, Gonzalez M, Daru V, Liprandi ' S. Implantable cardioverter defibrillators in patients with chagas disease: are they different from patients with coronary disease? Pacing Clin Electrophysiol. 1997; 20(1Pt 2):194-7.

71. Rassi A Jr, Rassi A. Another Disappointing Result With Implantable Cardioverter-Defibrillator Therapy in Patients With Chagas Disease. Europace. 2013;15(9):1383.

72. Rassi FM, Minohara L, Rassi A Jr, Correia LCL, Marin-Neto JA, Rassi A, et al. Systematic Review and Meta-Analysis of Clinical Outcome After Implantable Cardioverter-Defibrillator Therapy in Patients With Chagas Heart Disease. JACC Clin Electrophysiol. 2019;5(10):1213-23.

73. Andrade JP, Paola AA, Vilas-Boas F, Oliveira GM, Bacal F, Bocchi EA, et al. I Latin American Guideline for the Diagnosis and Treatment of Chagas' Heart Disease. Arq bras Cardiol. 2011;3(Suppl 2)::1- 48.

74. Gold MR, Van Veldhuisen DJ, Hauptman PJ, Borggrefe M, Kubo SH, Lieberman RA, et al. 2016. Vagus nerve stimulation for the treatment of heart failure: the INOVATE-HF trial. J Am Coll Cardiol. 2016; 68(2):149-58.

75. Zannad F, De Ferrari GM, Tuinenburg AE, Wright D, Brugada J, Butter C, et al. Chronic vagal stimulation for the treatment of low ejection fraction heart failure: results of the NEural Cardiac TherApy foR Heart Failure (NECTAR-HF) randomized controlled trial. Eur Heart J. 2015;36(7):425-33.

76. Behling A, Moraes RS, Rohde LE, Ferlin EL, Nóbrega AC, Ribeiro JP. Cholinergic stimulation with pyridostigmine reduces ventricular arrhythmia and enhances heart rate variability in heart failure. Am. Heart J. 2003;146(3):494-500.

77. Zhang, Y.H., Zhu, J., Song, Y.C. Suppressing sympathetic activation with clonidine on ventricular arrhythmias in congestive heart failure. Int. J. Cardiol. 1998; 65(3):233-8

78. Berta E, Confalonier P, Simoncini O, Bernardi G, Busnach G, Mantegazza R, et al. Removal of antiacetylcholine receptor antibodies by protein-A immunoadsorption in myasthenia gravis. Int J Artif Organs. 1994;17(11):603-8

79. Dörffel WV, Felix SB, Wallukat G, Brehme S, Bestvater K, Hofmann T, et al. Short-term hemodynamic effects of immunoadsorption in cilated cardiomyopathy. Circulation. 1997;95(8):1994-7.

80. Müller J, Wallukat G, Dandel M, Bieda H, Brandes K, Spiegelsberger S, et al. Immunoglobulin adsorption in patients with idiopathic dilated cardiomyopathy. Circulation. 2000;101(4):385-99.

81. Tura BR, Martino HF, Gowdak LH, dos Santos RR, Dohmann HF, Krieger JE, et al. Multicenter randomized trial of cell therapy in cardiopathies MiHeart Study. Trials. 2007;8:2 